\title{
- Research Note - \\ The Establishment of T-piece Cannula Fistulas into the Small Intestine of the Pig
}

\author{
Shu Furuya, Seiya Takahashi and Shoichiro Omori \\ National Institute of Animal Industry, Chiba-shi 280 \\ (Received July 12, 1973)
}

This paper describes a technique for establishing $T$-piece cannula fistulas in the pig small intestine and comparisons of growth and digestibility of fistulated pigs with those of nonfistulated pigs. Also, degree of leakage of digesta around cannulae was checked by measuring the chromic oxide recovery from the feces.

\section{Materials and Methods}

Design of cannula

A cannula consisted of a simple tubed barrel jointed to a guttertype flange made of $8 \mathrm{~mm}$, inside diameter, polyethylene tubing. The general shape of cannula with a external plastic collar and rubber stoppers is shown in Fig. 1, A. The ends of the cannula flange are rounded off with a sharp knife and the cannula rubbed down with emery paper to a smooth finish. For infusing test solutions into the intestine, a different type rubber stopper (right, in Fig. 1 , A) is used through which a tygon tube, $1 \mathrm{~mm}$ inside diameter, is put in.

Pre-operative management of the animals

Four female pigs, $30-40 \mathrm{~kg}$ body weight, were used for the operation. They were kept in wire digestion cages and fed a conventional diet for young pigs (88.1\% dry matter, $19.0 \%$ crude protein, $3.0 \%$ ether extract, $2.1 \%$ crude fibre, $58.0 \%$ nitrogen-free extract and $6.0 \%$ ash) ad libitum for a few days. Then, all feed was withheld 24 hours before operating, although the animals had free access to water.

Operative procedure

The animals were anesthetized with intramuscular sodium pentobarbital $(1 \mathrm{~m} l$ per $\mathrm{kg}$ body weight). As soon as anesthesia had been induced the animal was placed on an operating table. The technique described by MARKowIT $z^{11}$ was used to insert and to exteriorize the cannula. A $15 \mathrm{~cm}$ longitudinal incision was made in the abdomen $2 \mathrm{~cm}$ to the left of the mid-line. Each of three pigs was fitted with two $T$-piece cannulae, at the proximal jejunum $15 \mathrm{~cm}$ apart from the ligament of Treitz and at $2 \mathrm{~m}$ apart from the first one, and the other pig was fitted with one more cannula at the ileum approximately $15 \mathrm{~cm}$ from the ileo-caecal junction. A cannula was inserted into each of these points of intestinal tracts via a longitudinal jncision which was closed with a purse-string suture around the protruding tube to invert the edges of the exposed mucosa. The cannula was exteriorized by inserting a sharp trocar through the body wall in the region of the left flank. A small skin incision was used to facilitate passage of the trocar and the cannula. Each cannula was held in place externally with a plastic collar by a hose-type clamp. Positions of $T$-piece cannula fistulas in a pig 
A
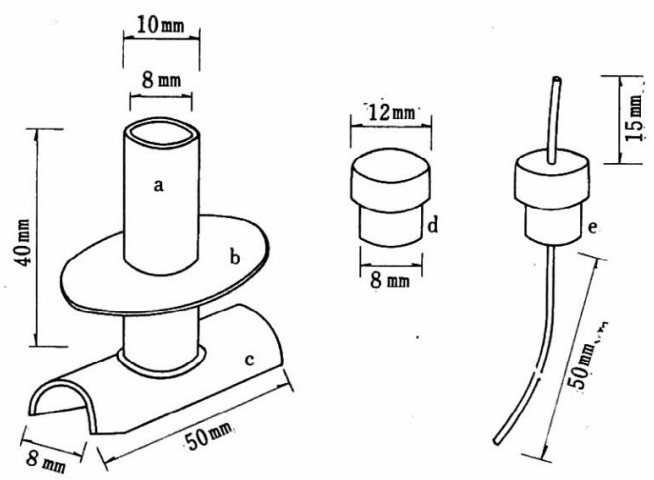

$\mathrm{B}$

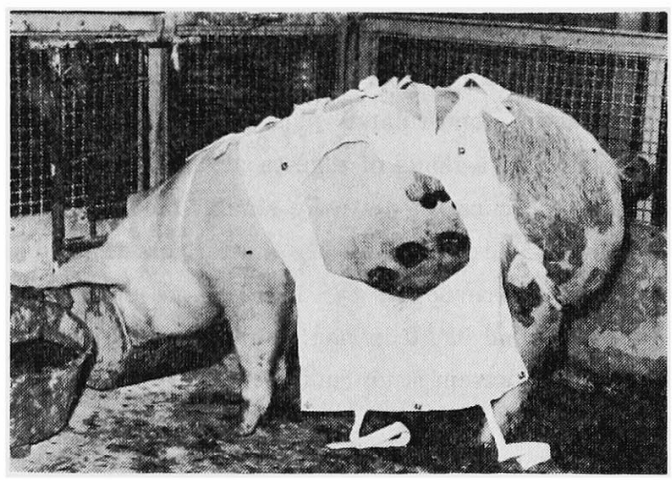

Fig. 1. A: Cannula consisted of a barrel (a) and a flange (c) with external collar (b) and two types of rubber stopper ( $\mathrm{d}$ and e). The right stopper (e) is used for infusing test solution. B: A pig fistulated with three $T$-piece cannulae. The left cannula and the middle one were in the jejunal region, $15 \mathrm{~cm}$ and $215 \mathrm{~cm}$ from the ligament of Treitz, respectively, and the right one was at the approximately $15 \mathrm{~cm}$ from the ileo-caecal junction.

photographed one month after the operation (Fig. 1, B). After the abdominal incision was closed, the pig was returned to its cage.

Post-operative management of the animal

Neither feed nor water was offered for the first 24 hours after operating. Thereafter, initially small but increasing amount of the diet was given. Daily intramuscular injections of penicillin G (800,000 I. U. per day) were given for five days. All the pigs made a rapid recovery from this operation, and seemed to return to normal state within one week.

\section{Growth and digestibility trials}

After the pigs recovered from the operation, daily gain, rate of gain, feed conversion, digestibility of the diet and chromic oxide recovery from the feces of four fistulated pigs were compared with those of two nonfistulated pigs. Pigs were placed in individual digestion cages and fed the same diet containing $1 \%$ chromic oxide twice daily, at 9 a.m. and 4 p.m., at a rate of $4 \%$ of initial body weight per day for one week. Water was offered ad libitum. They were weighed at the beginning and the end of the experiment. All the feces in the last 


\section{Furuya, Takahashi and Omori}

three days of one week experimental period were collected, dried in a forced-air oven at $60^{\circ} \mathrm{C}$, air-equilibrated, ground and sampled for analysis.

The analyses of fecal and diet moisture, crude protein, ether extract, crude fibre and ash were made according to conventional methods ${ }^{2}$. Chromic oxide was determined colorimetrically using the method of BRIsson ${ }^{3}$.

\section{Results and Diseussion}

The average daily gain was slightly higher in fistulated pigs than that in nonfistulated pigs, $656 \mathrm{~g}$ and $557 \mathrm{~g}$, respectively, but the average rate of gain expressed as a percentage of body weight gain in a week per initial body weight in fistulated and nonfistulated pigs were in agreement, $12.5 \%$ in either, because the average initial body weight in fistulated pigs was higher than that in nonfistulated pigs. Also, since the daily intake was limited to $4 \%$ of initial body weight, the feed conversion agreed between the two, 2.26.

The average value of the chromic oxide recoveries from the feces in fistulated pigs, $89 \%$, was slightly lower than that in nonfistulated pigs, $94 \%$. The difference between the two values seems to be a reflection of leakage of digesta around cannulae.

The digestibilities in all the constituents were similar between fistulated and nonfistulated pigs. The values (\%) with standard error of dry matter, crude protein, ether extract, crude fibre and nitrogen-free extract were $88 \pm 1,88 \pm 1,76 \pm 2,54 \pm 6$ and $94 \pm 1$ in fistulated pigs, and $88 \pm 1,88 \pm 1,80 \pm 2,44 \pm 2$ and $93 \pm 0$ in nonfistulated pigs, respectively.

These data obtained in the present study indicate that little stress was placed on fistulated pigs and suggest that study on the digestive process with fistulated pigs is conducted without disturbing their physiological conditions. All the pigs were in good condition for more than two months after the operation in spite of various sampling and infusing tests.

The authors wish to acknowledge their grateful thanks to Mrs. F. Usur for her valuable assistance, to Dr. M. Saito for his helpful discussion, and to Drs. S. Shibuya and K. Kameoka for their encouragement.

\section{References}

1) Markowitz, J., Experimental Surgery 3rd ed. 225-236. The Williams and Wilkins Company. Baltimore. 1954.

2) A.O.A.C., Official Methods of Analysis 9th ed. Association of Official Agricultural Chemists. Washington, D. C. 1960.

3) Brtsson, G.J., Can J Agr Sci 36: 210-212. 1956. 